\title{
DESCOLORAÇÃO BIOLÓGICA DO CORANTE TÊXTIL VERMELHO DO CONGO POR ESPÉCIES DE Aspergillus
}

\author{
J. R. GUIMARÃES ${ }^{1}$, L. S. CORDEIRO ${ }^{1}$, E. C. O. ARAÚJO ${ }^{1}$, I. R. SILVA ${ }^{1}$, R. J. S. \\ GONÇALVES ${ }^{1}$
${ }^{1}$ Universidade Federal de Campina Grande, Unidade Acadêmica de Engenharia de Bioprocessos e Biotecnologia
E-mail para contato: renatoge74@gmail.com

\begin{abstract}
RESUMO - Dos compostos responsáveis pela contaminação dos efluentes os corantes têxteis são os que causam mais danos ao meio ambiente. $\mathrm{O}$ surgimento de novas estratégias para o tratamento desses resíduos é de grande interesse industrial e econômico. Neste sentido, o objetivo deste trabalho foi analisar a degradação do corante vermelho congo utilizando fungos do gênero Aspergillus (A. flavus e A. fumigatus). Inicialmente, a análise ocorreu em placa de Petri com meio composto por $2 \%$ de batata (Solanum tuberosum), 1,5\% de Ágar e corante vermelho congo $(0,01 \%$ e $0,05 \%)$ para verificar a tolerância dos Aspergillus frente ao corante. A cultura fúngica dos Aspergillus foi inoculada em meio líquido contendo $1 \%$ de sacarose e $0,05 \%$ de corante vermelho congo, seguida de incubação sob condição estática na ausência de iluminação a $28{ }^{\circ} \mathrm{C}$ durante 15 dias. A descoloração do meio foi acompanhada através da redução nos valores de absorbância no comprimento de onda de $480 \mathrm{~nm}$. Após a fermentação, foi verificada a toxicidade do líquido utilizando o teste de crescimento de semente de feijão. Nestes ensaios foi possível constatar o crescimento das duas espécies de Aspergillus no meio reacional em ambas as concentrações de corante com melhor perfil para concentração de $0,05 \%$. No meio líquido, o A. flavus descoloriu $90,92 \%$ do meio, enquanto o A. fumigatus descoloriu $82,42 \%$, fato este que demonstra a eficiência destas espécies na degradação do presente corante. Quanto à toxicidade, o líquido da fermentação do A. flavus e do A. fumigatus apresentaram toxicidade não letal para as sementes de feijão.
\end{abstract}

\section{INTRODUÇÃO}

Atualmente, com o crescente desenvolvimento do setor industrial os problemas ambientais têm se tornado cada vez mais graves e frequentes. Dentro deste contexto, o setor têxtil apresenta um especial destaque sendo responsável por gerar grandes volumes de efluentes, os quais quando não tratados são altamente poluidores devido à presença de diversos compostos químicos utilizados na confecção dos tecidos. Todavia, os principais contaminantes dos efluentes têxteis são os corantes que não se fixam na fibra do tecido durante o processo de tingimento.

A poluição de corpos d'água com esses compostos compromete o equilíbrio ecológico e a saúde das comunidades, uma vez que os corantes pertencentes aos efluentes têxteis apresentam potencial carcinogênico, mutagênico, bioacumulativo, além de lenta degradação. 
De acordo com Morão (2014) tais corantes provocam diversos efeitos, tais como: a interdição da passagem de radiação solar prejudicando a biota vegetal aquática, mortalidade da biota, modificação reprodutiva, sobrevivência e desenvolvimento dos organismos.

A busca por alternativas de remoção destes corantes dos rejeitos industriais representa um dos maiores problemas ambientais enfrentados pelo setor na atualidade. Dentre as formas de tratamentos de efluentes têxteis existentes, o tratamento biológico evidencia-se como uma tecnologia em crescente expansão e, tem sido empregada na eliminação de corantes possibilitando sua remoção a um baixo custo por meio da utilização de diferentes microrganismos.

Entre os microrganismos com potencial para biorremediação, destacam-se os fungos. Alguns estudos os apontam como microrganismos promissores para o tratamento de efluentes têxteis, principalmente, devido ao fato de algumas espécies apresentarem a capacidade de descolorir e degradar diferentes compostos recalcitrantes (NETO et al., 2002). Esse potencial pode ser explicado pelo fato desses microrganismos conseguirem identificar os corantes, consumindo-os como nutrientes, começando dessa forma, um processo de absorção, sendo feita a transformação do corante em compostos mais simples que serão captados através dos filamentos do fungo (HANSEN, 2009).

Diante desta problemática ambiental que pode ocorrer pelo não tratamento dos efluentes da indústria têxtil e, considerando o potencial já demonstrado na literatura por fungos que promovem a biorremediação, este estudo teve como objetivo avaliar a capacidade de descoloração do corante têxtil vermelho congo por meio de fungos do gênero Aspergillus (Apergillus flavus e Aspergillus fumigatus) em meio sólido e líquido, além de testar a toxicidade do líquido fermentado.

\section{MATERIAL E MÉTODOS}

O experimento foi desenvolvido no Laboratório de Fitossanidade do Semiárido (LAFISA) da Universidade Federal de Campina Grande (UFCG), Campus Sumé - PB. Foram utilizadas duas espécies de fungos filamentosos do gênero Aspergillus (Aspergillus flavus e Aspergillus fumigatus) pertencentes a Micoteca CDSA do laboratório de Microbiologia da Universidade Federal de Campina Grande. Para a avaliação da capacidade de degradar o corante têxtil vermelho congo, os fungos foram cultivados inicialmente em meio BSA (2\% $(\mathrm{m} / \mathrm{v})$ de Batata, $1 \%(\mathrm{v} / \mathrm{v})$ de Sacarose e $1,5 \%(\mathrm{~m} / \mathrm{v})$ de Ágar) por 7 dias a $28{ }^{\circ} \mathrm{C}$ para a obtenção de colônias revigoradas. Posteriormente, para analisar a tolerância dos Aspergillus frente ao corante, discos de $0,5 \mathrm{~cm}$ de cada colônia foram inoculados em triplicata em placas de Petri contendo meio BA $(2 \%(\mathrm{~m} / \mathrm{v})$ de Batata e $1,5 \%(\mathrm{~m} / \mathrm{v})$ de Ágar) (controles) e BA suplementado com corante vermelho congo $(0,01 \%$ e $0,05 \%(\mathrm{~m} / \mathrm{v})$ para o Meio 1 e Meio 2, respectivamente). As placas foram incubadas sob condição estática na ausência de iluminação em BOD a $28{ }^{\circ} \mathrm{C}$ durante 15 dias. O perfil de crescimento (halo de formação da colônia) foi analisado como indicativo para a tolerância do fungo com relação ao corante, sendo quantificado após 7 e 15 dias de incubação.

Após análise da tolerância dos Aspergillus frente às duas concentrações de corante, foi utilizado para o ensaio de degradação em meio líquido a concentração que proporcionou melhor perfil de crescimento a ambos os fungos. O meio reacional foi composto por $2 \%(\mathrm{~m} / \mathrm{v})$ 
de Batata e $0,05 \%(\mathrm{~m} / \mathrm{v})$ de corante vermelho congo acrescido pela cultura fúngica dos Aspergillus (discos de 0,5 cm). O processo de degradação ocorreu durante 15 dias em condição estática e ausência de iluminação a $28{ }^{\circ} \mathrm{C}$. A degradação do corante foi verificada através da descoloração do meio reacional, utilizando como parâmetro a redução da absorbância no comprimento de onda $480 \mathrm{~nm}$ do liquido fermentado após 15 dias de fermentação. Ao término do processo de degradação, foi verificada a toxicidade do líquido utilizando o teste de crescimento de semente de feijão.

\section{RESULTADOS E DISCUSSÕES}

\subsection{Degradação em meio sólido - Teste de tolerância}

Dentre as duas espécies de Aspergillus analisadas, ambas foram capazes de crescer no meio de cultivo suplementado com o corante vermelho congo, mostrando assim possível potencialidade por intermédio desses microrganismos para o processo de degradação ou mesmo de adsorção dessa molécula em efluentes têxteis. Segundo Araújo et al. (2013), espécies do gênero Aspergillus (A. terreus e A. sclerotiorum) apresentam a capacidade de crescer na presença do corante Índigo Carmine, descolorindo o efluente de maneira eficiente.

$\mathrm{Na}$ avaliação do crescimento microbiano em meio sólido para o A. flavus e o A. fumigatus foi possível evidenciar a formação de perfis distintos quanto aos aspectos toxicológicos das concentrações do corante no meio frente estes Aspergillus (Tabela 1).

Tabela 1. Perfil de crescimento das colônias (em cm) dos Aspergillus durante 7 e 15 dias em meio BSA (controle), Meio 1 e Meio 2.

\begin{tabular}{ccccccc}
\hline \multirow{2}{*}{ Fungos } & \multicolumn{2}{c}{ BSA } & \multicolumn{2}{c}{ Meio 1 } & \multicolumn{2}{c}{ Meio 2 } \\
\cline { 2 - 7 } & $\mathbf{7 ~ d i a s}$ & $\mathbf{1 5}$ dias & $\mathbf{7 ~ d i a s}$ & $\mathbf{1 5}$ dias & $\mathbf{7 ~ d i a s}$ & $\mathbf{1 5}$ dias \\
\hline A.flavus & $7,3 \pm 0,05 *$ & $9 \pm 0$ & $1,76 \pm 0,16$ & $2,81 \pm 0,35$ & $2,21 \pm 0,32$ & $3,5 \pm 0,36$ \\
A. fumigatus & $6,9 \pm 0,1$ & $9 \pm 0$ & $5,75 \pm 0,67$ & $6,72 \pm 0,39$ & $5,93 \pm 0,62$ & $6,79 \pm 0,49$ \\
\hline
\end{tabular}

*Médias das quadruplicatas para os diâmetros de formação de colônia acompanhados com os respectivos desvios padrões.

Em observações com relação ao desempenho do A. flavus e do A. fumigatus realizadas após 7 e 15 dias de incubação, verificou-se que a velocidade instantânea de crescimento $(\mathrm{d} \phi \mathrm{x} / \mathrm{dt})$ foi influenciada pela concentração de corante no meio. A concentração de corante do Meio 2 proporcionou melhor velocidade de crescimento tanto para o A. flavus ( 7 dias: 0,276 cm.dia-1; 15 dias: 0,233 cm.dia ${ }^{-1}$ ) quanto para o A. fumigatus (7 dias: 0,741 cm.dia ${ }^{-1} ; 15$ dias: $0,453 \mathrm{~cm} \cdot \mathrm{dia}^{-1}$ ), o que demonstra que esta concentração é, dentre a analisada, ideal para verificar o processo de degradação do corante vermelho congo em meio líquido.

Assim, correlacionando os Aspergillus entre si com as duas concentrações do vermelho congo pode-se verificar que houve diferença significativa quanto ao parâmetro em estudo (d $\phi \mathrm{x} / \mathrm{dt})$, mostrando que o A. fumigatus é mais tolerante as concentrações de $0,01 \%$ e $0,05 \%$ do corante. O tempo de incubação foi uma variável que influenciou o processo de 
crescimento celular de forma negativa, tendo em vista a redução nas concentrações da fonte de carbono no meio.

\subsection{Degradação em meio líquido - Teste de tolerância e Toxicidade}

Na avaliação do processo de degradação do corante vermelho congo em meio líquido, foi possível evidenciar a formação de perfis distintos para os Aspergillus com relação a remoção desse corante no meio reacional. Dullius (2004) observou que espécies pertencentes ao gênero Aspergillus possuem alta capacidade para o processo de remoção de corante presente em efluentes.

Os presentes ensaios em meio líquido demonstraram que o A. flavus e o A. fumigatus podem ser utilizados para a biorremediação de corantes têxteis de maneira eficiente, pois apresentaram resultados de $90,92 \pm 0,33 \%$ e $82,42 \pm 2,84 \%$ de descoloração, respectivamente. Dellamatrice (2005) em seu experimento obteve resultados satisfatórios com algumas linhagens de Pleurotus sp. que conseguiram descolorir mais de 97\% do corante Índigo e 92\% do corante Remazol Brilliant Blue R (RBBR).

Quanto à toxicidade do produto degradado, o meio fermentado pelo A. flavus demonstrou maiores índices de germinação (100\%) e percentual de crescimento da raiz $(78,57 \%)$ para sementes de feijão, valores que diferem do A. fumigatus, que apresentou $66,67 \%$ de índice de germinação e $64,38 \%$ de percentual de crescimento da raiz.

\section{CONCLUSÕES}

- Os resultados demonstraram que os fungos (A. flavus e A. fumigatus) foram tolerantes à presença do corante têxtil vermelho congo em meio sólido.

- O fungo Aspergillus fumigatus apresentou a maior velocidade de crescimento $(0,741$ $\left.\mathrm{cm} \cdot \operatorname{dia}^{-1}\right)$;

- O fungo Aspergillus flavus apresentou maior potencial de descoloração (90,92 $\pm 0,33 \%)$ do meio reacional;

- O líquido proveniente da fermentação dos Aspergillus apresentou toxicidade não letal para as sementes de feijão.

\section{REFERENCIAS}

ARAÚJO, G. R.; BEZERRA, J. D. P.; FREIRE, K. T. L. S.; PAIVA, L. M.; SOUZA MOTTA, C. M.; MALOSSO, E.; SILVA, D. C. V. Descoloração do corante têxtil índigo carmine por espécies de Aspergillus. Universidade Católica de Pernambuco, Recife, PE, Brasil. 2013.

DULLIUS, C. H. Utilização de fungos para biodegradação de corantes têxteis sintéticos. Dissertação (Mestrado) - Programa de Pós- Graduação em desenvolvimento Regional, Universidade Santa Cruz do Sul, Santa Cruz do Sul, 2004. 
DELLAMATRICE, P. M. Biodegradação e toxicidade de corantes têxteis e efluentes da estação de Tratamento de Águas Residuárias de Americana, SP. Tese (Doutorado em Agricultura) - Universidade de São Paulo, Escola Superior de Agricultura "Luiz de Queiroz”. Piracicaba, 2005.

HANSEN, L.; LOPES, W.; RUSCHEL, C. K. Biorremediação - utilização do fungo Aspergillus niger no tratamento de efluentes. $24^{\mathrm{a}}$ Mostra Internacional de Ciência e Tecnologia. 2009.

MORÃO, L. G. Biossorção do corante DR 23 por Saccharomyces cerevisiae imobilizada em serragem de peroba (Aspidosperma polyneuron) tratada com PEI (polietilenoimina). 2014. 143f. Disssertação (mestrado em ciências biológicas) - Universidade Estadual Paulista, Instituto de Biociências, Rio Claro,2014.

NETO, J. M. C; SANTOS, A. Z.; TAVARES, C. R. G.; COSTA, S. M. G. Descoloração de corantes e efluentes têxteis utilizando fungos. ENCONTRO ANUAL DE INICIAÇÃO, 11, 2002, Maringá. Anais. Universidade Estadual de Maringá/ Pró- Reitoria de pesquisa e Pós- Graduação; 2002.

SILVA, M. F.; AZEVEDO, L. M. L.; GOMES, E. B.; SENNA, K. X. F. R.; MIRANDA, R. C. M.; GUSMÃO, N. B. Descoloração de efluentes têxteis por bactérias isoladas de ambientes contaminados por petroderivados. Simpósio nacional de bioprocessos, Natal. Anais. Natal: FAPESP, 2009.

PALÁCIO, S. M. Aplicação do processo de eletrocoagulação seguido por degradação fotocatalítica utilizando $\mathrm{TiO}_{2}$ no tratamento de efluente têxtil. 2009. Tese (Doutorado) Departamento de Química do Centro de Ciências Exatas, Universidade Estadual de Maringá. Maringá, 2009. 